\title{
Do patients of integrative anthroposophic pediatric inpatient departments differ? Comparative analysis to all pediatric inpatients in Germany considering demographic and clinical characteristics
}

Katharina Fetz ${ }^{1 *} \mathbb{D}$, Thomas Ostermann ${ }^{1}$, Melanie Schwermer ${ }^{2}$, Sebastian Appelbaum ${ }^{1}$, Jan Vagedes ${ }^{3,4}$, Tycho Jan Zuzak ${ }^{2,5}$ and Alfred Längler ${ }^{2,6}$

\begin{abstract}
Background: Integrative medicine (IM) is a patient-centered, evidence-based, therapeutic paradigm which combines conventional and complementary approaches. The use of IM in pediatrics has increased in the past two decades and parents' demand for it is growing. An IM whole systems approach is anthroposophic medicine. Considering the growing demand for integrative approaches in children, it is relevant from a public health perspective to find out which kind of children use IM in Germany and whether they differ from the entirety of pediatric inpatients in Germany. Moreover, it would be interesting to known, whether these patients are willing to travel a longer distance to gain integrative treatment.

Methods: The present study investigates the standard ward documentation datasets of 29,956 patients of all German integrative anthroposophic pediatric inpatient wards from 2005 to 2016 and compares them systematically to collect data of the entirety of all pediatric inpatient wards in Germany. Apart from patients' age and gender, and the ICD-10 admission diagnoses, the geographical catchment area of the hospitals were analyzed.

Results: Sociodemographic characteristics of pediatric inpatients in the integrative anthroposophic departments $(\mathrm{IAH})$ did not differ from the entirety of all pediatric inpatients. Regarding clinical characteristics, higher frequencies were found for endocrine, nutritional and metabolic diseases (IAH: 7.24\% vs. 2.98\%); mental, behavioral, and neurodevelopmental disorders (IAH: 9.83\% vs. 3.78\%) and nervous diseases (IAH: 8.82\% vs. 5.16\%) and lower frequencies for general pediatric diseases such as respiratory diseases (IAH: 17.06\% vs. 19.83\%), digestive diseases (IAH: $3.90 \%$ vs. 6.25\%), and infectious and parasitic diseases (IAH: $12.88 \%$ vs. 14.82\%) in comparison to the entirety of all pediatric inpatients in Germany. The IAH showed a broad catchment area, with most patients being from former, Western federal republic of Germany. Large catchment areas (> $100 \mathrm{~km})$ for the IAH are merely covered by severe and chronic diseases.

* Correspondence: Katharina.fetz@uni-wh.de

${ }^{1}$ Department of Psychology and Psychotherapy, Chair of Research

Methodology and Statistics in Psychology, Witten/Herdecke University,

Alfred-Herrhausen-Straße 50, 58448 Witten, Germany

Full list of author information is available at the end of the article

(c) The Author(s). 2019 Open Access This article is distributed under the terms of the Creative Commons Attribution 4.0 International License (http://creativecommons.org/licenses/by/4.0/), which permits unrestricted use, distribution, and reproduction in any medium, provided you give appropriate credit to the original author(s) and the source, provide a link to the Creative Commons license, and indicate if changes were made. The Creative Commons Public Domain Dedication waiver (http://creativecommons.org/publicdomain/zero/1.0/) applies to the data made available in this article, unless otherwise stated. 
(Continued from previous page)

Conclusion: Pediatric inpatients of IAH do not differ from the entirety of pediatric inpatients in Germany regarding sociodemographic characteristics but show differences regarding clinical characteristics. Parents are willing to travel further distance to get specialized integrative anthroposophic medical care for children with severe and chronic diseases.

Keywords: Integrative medicine, Pediatrics, Patient characteristics, Catchment area, Epidemiology, Anthroposophic medicine

\section{Background}

Over the last 20 years, the term "Integrative medicine" has frequently been used in different healthcare sectors and systems to describe health services models that make "use of all appropriate therapeutic and lifestyle approaches, healthcare professionals and disciplines to achieve optimal health and healing" for the patient [1]. As a patient-centered, evidence-based, therapeutic paradigm it combines conventional and complementary approaches to foster patient health and addresses biological, psychosocial, spiritual, and environmental aspects of patients' wellbeing [2]. Health care professionals of integrative medicine vary depending on the country's health care system and its national and local regulations but commonly include physicians and non-medical therapists with are "succinct, explicit, and transparent for the integration and subsequent collaboration when treating patients" [3].

In western countries, integrative healthcare approaches have mostly emerged from primary care and, depending on the underlying healthcare system, found their way into secondary and tertiary patient care. In Europe, this has led to specialized hospitals and departments delivering integrative approaches with specializations in natural medicine, homeopathy, anthroposophic medicine or Traditional Chinese medicine [4-11]. In the United States integrative treatment approaches are fostered by the National Center for Complementary and Integrative Health $(\mathrm{NCCIH})$ and have led to the formation of the Consortium of Academic Health Centers for Integrative Medicine [12] which currently includes more than 50 programs and centers.

The clinical use of integrative approaches in pediatrics has increased in the past two decades [2, 4, 6, 13-21]. Integrative medicine is used in children in the US [15, 17, 22-25], Canada [26] and in Europe [4, 6-9, 27, 28]. Integrative medicine for children is provided in private practices, outpatient wards, as well as inpatient wards [8].

Several recent studies report that $30-50 \%$ of parents of children with acute or chronic diseases state using integrative medicine for their child [11, 29-31]. The use of integrative medicine seems to be more frequent (>50\%) in children with chronic diseases in the US [22, 32-37]. Factors that are associated with the use of integrative medicine in children are the severity of their disease as well as parents' use of integrative approaches [14, 38]. It is particularly prominent among affluent and educated parents [39]. A prospective cohort study on holistic pediatric services for inpatients and outpatients in oncology reports nausea, pain, insomnia, and agitation to be the most frequent goals for consultation of integrative medicine in children, as well as questions about herbs, dietary supplements, diet and nutrition, and mind-body therapies, such as guided imagery and biofeedback, and massage [17]. A recent review found a growing establishment of pediatric integrative medicine in academic hospitals in the US and describes pediatric integrative medicine to be a much-needed subspecialty to meet the needs of today's children [2]. Integrative medicine is especially relevant for pediatric gastroenterology, pain medicine, neurology, oncology, pulmonary and other subspecialties in the US [2]. A very recent study in a large pediatric hospital in the US [19] found that anecdotal and scientific evidence supported the use of integrative approaches in the context of pediatrics.

Two recent publications by Eckert et al. [6] and Anheyer et al. [4] describe the successful implementation of integrative pediatrics at pediatric hospitals in Germany (St Marien, Landshut, Elisabeth hospital Essen) for inpatient and outpatient services. Modalities applied are TCM, relaxation, hypnosis, reflexology, compresses and poultices, aromatherapy, homeopathy, yoga and herbal medicine as well as phytotherapeutic approaches [4]. Optional single-remedy-homeopathy is being integrated into routine pediatric service at the Dr. von Hauner's Children's University hospital in Munich [40, 41].

A well-known and frequently used integrative whole systems approach in Germany is anthroposophic medicine [42]. Anthroposophic medicine is based on a holistic understanding of humans and nature and of disease and treatment. The anthroposophic approach is based on a concept of four levels of formative forces and on the model of a three-fold human constitution [42]. It uses medical remedies derived from plants, minerals, and animals, art therapy, eurythmy therapy, and rhythmical massage, counseling, psychotherapy, and specific nursing techniques such as external embrocation [43-45]. Anthroposophic medicine has established therapeutic recommendations for the treatment 
of children suffering acute gastroenteritis [44], pseudocroup [43], bronchitis [45] and epilepsy. In Germany, there are two pediatric inpatient departments with a distinct focus on integrative anthroposophic medicine, at the Gemeinschaftskrankenhaus Herdecke (community hospital) and the Filderklinik Filderstadt $[8,10]$. Even though there is a growing interest of parents on integrative pediatrics, little is known about the inpatient treatment infra-structure, disease burden and patient characteristics.

Until today, most of the available information on pediatric inpatients using integrative medicine is based on qualitative analyses $[4,6]$, while systematic quantitative analyses of patient characteristics and diagnosis parameters are lacking. Considering the growing demand for integrative approaches and the increasing number of institutions offering and implementing integrative medicine for children [17], it is relevant from a public health perspective to investigate which kind of patients make use of integrative approaches in Germany. In particular, it is of interest whether these patients differ from the entirety of pediatric patients in Germany concerning clinical and demographic characteristics. It has been suggested by previous studies that especially patients with severe $[14,38]$ and chronic diseases use integrative approaches [22, 32-37] and patients may be willing to travel longer distances to be treated in a hospital with special offers [46] it would be interesting to known, whether these patients are also willing to travel a longer distance to gain integrative treatment, such as anthroposophic medicine. Furthermore, earlier studies have shown that there seems to be a difference between Western Germany and former Eastern Germany considering the use of integrative medicine [47], consequently it would be relevant to know whether there are similar patterns for integrative pediatric patients.

Therefore, the current study aims to investigate patient characteristics and diagnosis parameters of integrative anthroposophic pediatric inpatients and to compare them to data from all pediatric wards in Germany. Our hypotheses were that:

1. Pediatric inpatients treated in these departments do not differ from other German pediatric inpatients concerning demographic characteristics.

2. Pediatric inpatients treated in these departments do not differ from other German pediatric inpatients concerning clinical characteristics.

3. Anthroposophic pediatric inpatient departments have a broad catchment area all over Germany. We hypothesize a higher number of patients from Western Germany in comparison to Eastern Germany. Additionally, we hypothesized that patients with a long travel distance to either one of the hospitals have chronic diseases and patients with a short travel distance predominantly acute disease.

\section{Methods \\ Study design}

The current study is based on a secondary data analysis of hospital routine admission and discharge data as reported to the Institute for the Hospital Reimbursement System (InEK) pursuant to paragraph 21 of the German Hospital Remuneration Act. Collection and submission of this data is mandatory for all German hospitals and is defined by the patient's gender, age, length of hospital stay, postcode area, diagnoses based on the International Classification of Diseases (ICD-10) diagnosis groups, comorbidities and further factors related to the hospitalization. It was conducted according to the Declaration of Helsinki [48] and reported according to the STROBE guidelines [49] for reporting observational cohort studies. A permission from the data security officers of both hospitals for the use of patient data within this study was obtained.

\section{Setting}

In Germany, there are two integrative hospitals focusing on integrative pediatric inpatient care with a focus on anthroposophic medicine: The Gemeinschaftskrankenhaus in Herdecke and the Filderklinik in Filderstadt. Both hospitals treat children with various diseases reaching from general pediatrics to specialized fields as e.g. neonatology, pediatric oncology, and diabetes by means of an integrative approach provided by specialized physicians in integrative pediatrics combining conventional and complementary therapies. The staff includes nurses, pharmacists and therapists trained in integrative medicine. Diagnosis and treatment are delivered in accordance with official pediatric guidelines but include optional treatment of anthroposophic medicine [43, 44] including complementary pharmacotherapy, medicinal baths, rhythmical massages, compresses, and embrocation (rhythmic massages with etheric oils e.g. [50]) as well as art therapy, eurythmy, speech therapies, music therapy [51], and light/ color therapy [52]). Both hospitals are part of the regular medical care and thus funded by the statutory health insurers.

The pediatric ward of the Filderklinik treats on average 1245 patients per year (2005-2016). Apart from general pediatrics, the Filderklinik specifies in epileptology, psychosomatic disorders, neonatology, and cardiology for children. The Filderklinik is an academic teaching hospital of the University of Tubingen.

In the pediatric department of the Gemeinschaftskrankenhaus Herdecke 1750 patients are treated averagely every year (2005-2016). At the department children with a wide spectrum of diseases are being treated; including 
approaches from diabetology, oncology, neonatology, rheumatology, psychosomatic medicine, and neurology alongside general pediatrics. The Gemeinschaftskrankenhaus is an academic teaching hospital of Witten/Herdecke university.

\section{Data collection and eligibility criteria}

Patient data from both integrative anthroposophic hospitals between 2005 and 2016 were derived from the yearly datasets collected in fulfilment of the German Hospital Remuneration Act. These data are a full sample of all cases and patients giving reasons for admission and discharge with the respective dates. Data were extracted from the hospital documentation system and then transferred into SPSS 24. (IBM). Plausibility checks of all variables were performed prior to data analysis. All data were processed anonymously. Individual patient identification was not possible at any time. Data of the entirety of all pediatric departments in Germany including the anthroposophic hospitals were obtained from the German Federal Statistical Office (Destatis), which collects these data annually in a cumulated form.

Patient characteristics of interest were age, gender and status of insurance. Catchment area was estimated as suggested by Ehara [53]. The distance from patients' place of residence to either the Gemeinschaftskrankenhaus or the Filderklinik was calculated using Microsoft Excels function "get distance" by means of patients' zip codes to obtain the catchment area of both hospitals. Additionally, zip codes were used to distinguish between federal states of former Western and Eastern Germany in the analyses. Diagnostic parameters were described in terms of the ICD-10-chapter headings.

\section{Statistical analysis}

All data were analyzed using nonparametric univariate statistics (e.g. Wilcoxon-Test or Chi-Square-Test). Because data from comparable departments were only available as cumulative data, further multivariate analyses were not possible. All statistical analyses were performed using IBM SPSS Version 24.

\section{Results}

\section{Patient characteristics}

The integrative anthroposophic sample includes $N=29$, 956 separate admissions (Gemeinschaftskrankenhaus Herdecke: $n=17,503$ (58.4\%); Filderklinik Filderstadt: $n=12,453(41.6 \%)$. The entirety of all pediatric inpatients in Germany consisted of 8,645,173 cases. Patients in the integrative anthroposophic sample were on average $47.6 \%$ female showing no difference compared to the percentage of $46.8 \%$ of females in the entirety. Age distribution in both samples was right skewed with a median age in the integrative anthroposophic sample of 3 years and a mean age of 5.58 years $(\mathrm{SD}=5.90)$ while in the entirety the median age was 3.5 years with a mean of 5.63 years. ( $\mathrm{SD}=5.81)$. Wilcoxon test revealed no statistically significant mean difference concerning mean age between the integrative anthroposophic and the entirety sample $(z=-1.49 ; p=.14)$.

\section{Diagnostic parameters ICD-diagnoses}

Most frequent ICD-chapters in the integrative anthroposophic sample (IAH) were diseases of the respiratory system $(n=5019 ; 17.06 \%)$, certain infectious and parasitic diseases $(n=3859 ; 12.88 \%)$, and certain conditions originating in the perinatal period $(n=3547 ; 11.84 \%)$. In the entirety of all pediatric inpatient wards, most frequent diseases were diseases of the respiratory system $(n=1,714,182 ; 19.83 \%)$ and certain infectious and parasitic diseases ( $n=1,281,000 ; 14.82 \%)$, and injury, poisoning and certain other consequences of external causes $(n=999,233 ; 11.56 \%)$.

Higher frequencies were found for endocrine, nutritional and metabolic diseases (IAH: $7.24 \%$ vs. $2.98 \%$ ); mental, behavioral and neurodevelopmental disorders (IAH: $9.83 \%$ vs. $3.78 \%$ ) and diseases of the nervous system (IAH: $8.82 \%$ vs. $5.16 \%$ ) and lower frequencies for general pediatric diseases such as respiratory diseases (IAH: $17.06 \%$ vs. $19.83 \%$ ), diseases of the digestive system (IAH: $3.90 \%$ vs. $6.25 \%$ ), and infectious and parasitic diseases (IAH: $12.88 \%$ vs. $14.82 \%$ ) in comparison to the entirety of all pediatric inpatients in Germany.

An overview of the frequencies and percentages of all ICD-10-chapters in the integrative anthroposophic pediatric hospitals and the entirety of all pediatric hospitals in Germany is provided in Table 1.

\section{Catchment area}

The catchment areas of the integrative anthroposophic pediatric inpatient wards are illustrated in Fig. 1. The mean distance from patients' place of residence to one of the hospitals was $61.84 \mathrm{~km}(\mathrm{SD}=170.27 \mathrm{~km})$. Almost one third (9673 patients; $32.40 \%$ ) came from the very local catchment area $(<10 \mathrm{~km}), 13,949(46.80 \%)$ came from regional catchment areas (10-50 km), 2573 (8.6\%) came from an extended catchment area between 50 and $100 \mathrm{~km}$ and $3614(12.1 \%)$ came from a supra-regional catchment area $(>100 \mathrm{~km})$. A significant difference in the number of patients was observed between former Western Germany ( $n=29,590 ; 99.2 \%)$ and former Eastern Germany ( $n=250 ; 0.8 \%)$.

The catchment area groups for the ICD-10 chapters are shown in detail in Table 2. Chi-Square test revealed significant differences between the ICD-10 groups concerning group of catchment area $\left(\mathrm{Chi}^{2}=5765.28 ; p<.001\right)$. Causes like pregnancy, childbirth and the puerperium, 
Table 1 Frequencies of ICD chapters in the integrative anthroposophic pediatric inpatient departments and in the entirety of all pediatric inpatient departments

\begin{tabular}{|c|c|c|c|c|c|}
\hline \multicolumn{2}{|c|}{ ICD-10 chapter } & \multicolumn{2}{|c|}{$\begin{array}{l}\text { integrative anthroposophic pediatric } \\
\text { hospitals }\end{array}$} & \multicolumn{2}{|c|}{$\begin{array}{l}\text { entirety of allpediatric } \\
\text { hospitals }\end{array}$} \\
\hline & & \multirow{2}{*}{$\frac{n}{3859}$} & \multirow{2}{*}{$\frac{\%}{12.88 \%}$} & \multirow{2}{*}{$\frac{n}{1,281,000}$} & \multirow{2}{*}{$\begin{array}{l}\% \\
14.82 \%\end{array}$} \\
\hline A00 - B99 & Certain infectious and parasitic diseases & & & & \\
\hline C00 - D48 & Neoplasms & 1140 & $3.81 \%$ & 264,457 & $3.06 \%$ \\
\hline D50 - D90 & $\begin{array}{l}\text { Diseases of the blood and blood-forming organs and } \\
\text { certain disorders involving the immune mechanism }\end{array}$ & 277 & $0.92 \%$ & 107,363 & $1.24 \%$ \\
\hline E00 - E90 & Endocrine, nutritional and metabolic diseases & 2168 & $7.24 \%$ & 257,599 & $2.98 \%$ \\
\hline F00 - F99 & Mental, behavioral and neurodevelopmental disorders & 2946 & $9.83 \%$ & 327,029 & $3.78 \%$ \\
\hline G00 - G99 & Diseases of the nervous system & 2642 & $8.82 \%$ & 445,815 & $5.16 \%$ \\
\hline H0O - H59 & Diseases of the eye and adnexa & 68 & $0.23 \%$ & 45,996 & $0.53 \%$ \\
\hline H60 - H95 & Diseases of the ear and mastoid process & 172 & $0.57 \%$ & 76,118 & $0.88 \%$ \\
\hline $100-199$ & Diseases of the circulatory system & 200 & $0.67 \%$ & 116,836 & $1.35 \%$ \\
\hline$J 00-J 99$ & Diseases of the respiratory system & 5109 & $17.06 \%$ & $1,714,182$ & $19.83 \%$ \\
\hline K00 - K93 & Diseases of the digestive system & 1168 & $3.90 \%$ & 540,752 & $6.25 \%$ \\
\hline L00 - L99 & Diseases of the skin and subcutaneous tissue & 499 & $1.67 \%$ & 156,706 & $1.81 \%$ \\
\hline M00 - M99 & $\begin{array}{l}\text { Diseases of the musculoskeletal system and connective } \\
\text { tissue }\end{array}$ & 433 & $1.45 \%$ & 174,555 & $2.02 \%$ \\
\hline N00 - N99 & Diseases of the genitourinary system & 588 & $1.96 \%$ & 247,691 & $2.87 \%$ \\
\hline O00 - O99 & Pregnancy, childbirth and the puerperium & 8 & $0.03 \%$ & 970 & $0.01 \%$ \\
\hline P00 - P99 & Certain conditions originating in the perinatal period & 3547 & $11.84 \%$ & 640,136 & $7.40 \%$ \\
\hline Q00 - Q99 & $\begin{array}{l}\text { Congenital malformations, deformations and chromosomal } \\
\text { abnormalities }\end{array}$ & 473 & $1.58 \%$ & 168,625 & $1.95 \%$ \\
\hline R00 - R99 & $\begin{array}{l}\text { Symptoms, signs and abnormal clinical and laboratory } \\
\text { findings, not elsewhere classified }\end{array}$ & 1550 & $5.17 \%$ & 840,874 & $9.73 \%$ \\
\hline S00 - T98 & $\begin{array}{l}\text { Injury, poisoning and certain other consequences of } \\
\text { external causes }\end{array}$ & 2950 & $9.85 \%$ & 999,233 & $11.56 \%$ \\
\hline Zoo - Z99 & External causes of morbidity & 0 & $0.00 \%$ & 239,055 & $2.77 \%$ \\
\hline U00 - U99 & $\begin{array}{l}\text { Factors influencing health status and contact with } \\
\text { health services }\end{array}$ & 159 & $0.53 \%$ & 29 & $0.00 \%$ \\
\hline N & & 29,956 & $100.00 \%$ & $8,645,021$ & $100.00 \%$ \\
\hline
\end{tabular}

injuries \& poisonings, and diseases of the circulatory system were more locally centered around the hospitals, while diseases of the nervous system, musculoskeletal disorders and neoplasms were reason for patients from more outlying areas to choose one of these hospitals.

\section{Discussion}

The aim of our study was to investigate patient characteristics and diagnosis parameters of integrative anthroposophic pediatric inpatients and compare them to data from all pediatric wards in Germany. We found no difference between pediatric patients in the integrative anthroposophic hospitals and the entirety of all pediatric hospitals concerning age and gender distribution. We furthermore hypothesized that patients treated in these department do not differ from the entirety considering clinical characteristics, such as the frequency of the ICD-10 diagnoses. Our findings did not support this hypothesis; in fact, our data indicated that the situation is much more complex. While there are disease categories that show great similarities in their frequencies compared to the entirety of all pediatric departments in Germany such as diseases of the skin and subcutaneous tissue, congenital malformations and deformations and chromosomal abnormalities, we found comparatively higher frequencies for perinatal, neurological and behavioral diseases. Moreover, we found lower frequencies for diseases from the field of general pediatrics such as digestive diseases, respiratory diseases, and infectious and parasitic diseases. Our data showed a broad catchment area for the integrative anthroposophic pediatric hospitals with a significantly higher number of patients from the former Western part of Germany compared to the former Eastern part. We were furthermore able to demonstrate, that patients with a long travel distance to either one of the integrative anthroposophic hospitals 


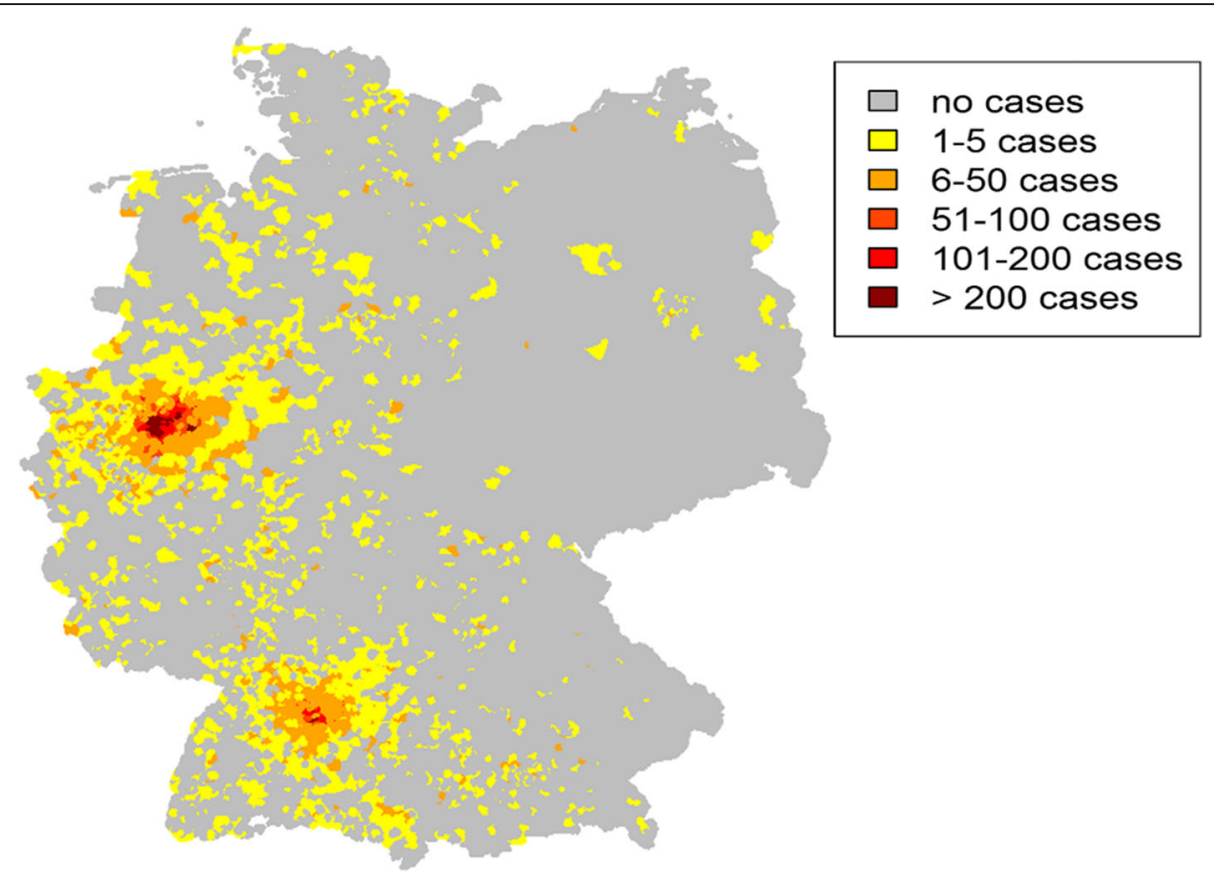

Fig. 1 Catchment area of the integrative anthroposophic pediatric inpatient departments in Germany. This heatmap was created based on patients' postal code data using R Statistical Computing

have chronic diseases and patients with a short travel distance predominantly acute disease.

\section{Comparison to previous findings}

In line with former research our data suggests that integrative medicine for children is used for acute as well as chronic diseases [11, 29-31]. Our results showed a higher number of pediatric inpatients with endocrine, nutritional and metabolic diseases, mental, behavioral and neurodevelopmental diseases, nervous diseases and perinatal diseases in comparison to the entirety of pediatric inpatient departments in Germany. This circumstance may most likely be due to the certain specializations of the integrative anthroposophic hospitals. However, these diseases also tend to be severe and chronic diseases. In line with this, earlier research showed the use of integrative medicine to be more frequent in children with severe and chronic diseases [14, 22, 32-38].

In our study, the most frequent diseases in the integrative anthroposophic pediatric inpatient departments were respiratory diseases, infectious and parasitic diseases, and perinatal diseases. In contrast, other studies on integrative pediatric in- and outpatient service found nausea, pain, insomnia, and agitation to be the most frequent consultation indications [17]. This difference is most likely due to the oncological setting of this study, which shows a limited comparability to our study setting and patients. In line with a current review [2] we found suggestions that integrative medicine for children is a much-needed subspecialty to meet the need of today's children and that it shows specific relevance for certain disciplines. In line with previous research [47] we found a larger number of patients using integrative pediatrics from former Western Germany in comparison to former Eastern Germany.

While most of the ICD-10 categories had a local and regional catchment area, the supra-regional catchment area $(>100 \mathrm{~km})$ seems to be merely covered by children treated for diseases of the nervous system, neoplasms and diseases of the musculoskeletal system and connective tissue. This circumstance is not surprising as these diseases are part of the specialties of both hospitals. In accordance with findings of (Adams 1991) it seems plausible that parents of patients with these diseases take a longer travel time to the hospital to get treated in one of the specialized integrative anthroposophic hospitals. It is in line with earlier research reporting that parents of children with chronic and severe diseases use integrative medicine more frequently [22, 32-37]. In line with our results, a recent study [54] found a large catchment area $(138 \mathrm{~km})$ for children with chronic pain treated in a specialized pediatric chronic pain ward in Germany. This result was interpreted as an indicator for inadequate resources in other regions. However, in other studies larger catchment areas were also found in hospitals specialized i.e. in knee 
Table 2 Catchment area and ICD-10 chapters of the integrative anthroposophic pediatric inpatient departments

\begin{tabular}{|c|c|c|c|c|c|c|c|c|c|c|}
\hline \multirow{3}{*}{$\begin{array}{l}\text { ICD-10 chapter } \\
\text { Certain infectious and parasitic diseases }\end{array}$} & \multicolumn{10}{|c|}{ catchment area } \\
\hline & \multicolumn{2}{|c|}{$\begin{array}{l}\text { local } \\
<10 \mathrm{~km}\end{array}$} & \multicolumn{2}{|c|}{$\begin{array}{l}\text { regional } \\
10-50 \mathrm{~km}\end{array}$} & \multicolumn{2}{|c|}{$\begin{array}{l}\text { extended } \\
50-100 \mathrm{~km}\end{array}$} & \multicolumn{2}{|c|}{$\begin{array}{l}\text { supraregional } \\
>100 \mathrm{~km}\end{array}$} & \multicolumn{2}{|l|}{ overall } \\
\hline & 1578 & $16 \%$ & 1808 & $13 \%$ & 223 & $9 \%$ & 239 & $7 \%$ & 3848 & $13 \%$ \\
\hline Neoplasms & 169 & $2 \%$ & 495 & $4 \%$ & 167 & $6 \%$ & 294 & $8 \%$ & 1125 & $4 \%$ \\
\hline $\begin{array}{l}\text { Diseases of the blood and blood-forming organs and } \\
\text { certain disorders involving the immune mechanism }\end{array}$ & 66 & $1 \%$ & 145 & $1 \%$ & 39 & $2 \%$ & 27 & $1 \%$ & 277 & $1 \%$ \\
\hline Endocrine, nutritional and metabolic diseases & 359 & $4 \%$ & 1173 & $8 \%$ & 353 & $14 \%$ & 275 & $8 \%$ & 2160 & $7 \%$ \\
\hline Mental, behavioral and neurodevelopmental disorders & 562 & $6 \%$ & 1330 & $10 \%$ & 434 & $17 \%$ & 605 & $17 \%$ & 2931 & $10 \%$ \\
\hline Diseases of the nervous system & 408 & $4 \%$ & 845 & $6 \%$ & 272 & $11 \%$ & 1050 & $29 \%$ & 2575 & $9 \%$ \\
\hline Diseases of the eye and adnexa & 19 & $0 \%$ & 39 & $0 \%$ & 7 & $0 \%$ & 3 & $0 \%$ & 68 & $0 \%$ \\
\hline Diseases of the ear and mastoid process & 56 & $1 \%$ & 94 & $1 \%$ & 11 & $0 \%$ & 11 & $0 \%$ & 172 & $1 \%$ \\
\hline Diseases of the circulatory system & 98 & $1 \%$ & 77 & $1 \%$ & 10 & $0 \%$ & 15 & $0 \%$ & 200 & $1 \%$ \\
\hline Diseases of the respiratory system & 1965 & $20 \%$ & 2541 & $18 \%$ & 354 & $14 \%$ & 240 & $7 \%$ & 5100 & $17 \%$ \\
\hline Diseases of the digestive system & 394 & $4 \%$ & 538 & $4 \%$ & 105 & $4 \%$ & 129 & $4 \%$ & 1166 & $4 \%$ \\
\hline Diseases of the skin and subcutaneous tissue & 125 & $1 \%$ & 234 & $2 \%$ & 61 & $2 \%$ & 78 & $2 \%$ & 498 & $2 \%$ \\
\hline $\begin{array}{l}\text { Diseases of the musculoskeletal system and connective } \\
\text { tissue }\end{array}$ & 70 & $1 \%$ & 162 & $1 \%$ & 37 & $1 \%$ & 163 & $5 \%$ & 432 & $1 \%$ \\
\hline Diseases of the genitourinary system & 215 & $2 \%$ & 292 & $2 \%$ & 35 & $1 \%$ & 44 & $1 \%$ & 586 & $2 \%$ \\
\hline Pregnancy, childbirth and the puerperium & 0 & $0 \%$ & 8 & $0 \%$ & 0 & $0 \%$ & 0 & $0 \%$ & 8 & $0 \%$ \\
\hline Certain conditions originating in the perinatal period & 979 & $10 \%$ & 2177 & $16 \%$ & 232 & $9 \%$ & 152 & $4 \%$ & 3540 & $12 \%$ \\
\hline Congenital malformations, deformations and chromosomal abnormalities & 128 & $1 \%$ & 246 & $2 \%$ & 42 & $2 \%$ & 56 & $2 \%$ & 472 & $2 \%$ \\
\hline $\begin{array}{l}\text { Symptoms, signs and abnormal clinical and laboratory findings, } \\
\text { not elsewhere classified }\end{array}$ & 641 & $7 \%$ & 682 & $5 \%$ & 119 & $5 \%$ & 104 & $3 \%$ & 1546 & $5 \%$ \\
\hline Injury, poisoning and certain other consequences of external causes & 1768 & $18 \%$ & 1009 & $7 \%$ & 64 & $2 \%$ & 105 & $3 \%$ & 2946 & $10 \%$ \\
\hline Factors influencing health status and contact with health services & 73 & $1 \%$ & 54 & $0 \%$ & 8 & $0 \%$ & 24 & $1 \%$ & 159 & $1 \%$ \\
\hline overall & 9673 & & 13,949 & & 2573 & & 3614 & & 29,809 & \\
\hline
\end{tabular}

surgery [55]. Thus, a broad catchment area can also be interpreted as an indicator of quality of care. Currently, there is a trend towards a centralization of specific healthcare supply in particular in the hospital sector in the German healthcare system [56]. There seems to be a comparable pattern within integrative anthroposophic pediatrics as a highly specialized treatment approach.

\section{Comparison to other integrative services in Germany}

The present study investigated patients of two specialized integrative pediatric inpatient departments with a distinct focus on anthroposophic medicine. While these departments are not the only institutions offering integrative approaches for children there are some differences in the kind of integrative healthcare service offered: The Elisabeth hospital in Essen [4] and St Marien hospital in Landshut [6] offer consultancy for pediatric inpatients and outpatients. In contrast to this approach, integrative anthroposophic hospitals have fully implemented integrative approaches into the daily clinical routine for all patients admitted.

\section{Strengths and limitations}

With our study we aimed to contribute to the better understanding of patient populations using pediatric integrative medicine in Germany. To our knowledge, this is the first systematic comparison of a large sample of integrative pediatric patients to the entirety of pediatric inpatients in Germany. A significant limitation of our study is that in consequence of being a secondary data analysis some subgroup comparisons were not possible, because we were only able to get cumulated data from the German Federal Statistical Office. In particular, there were no data available concerning the catchment areas of other pediatric inpatient departments to compare our data to.

\section{Conclusions}

In line with our hypothesis, pediatric inpatients of integrative anthroposophic inpatient departments do not differ from the entirety of pediatric inpatients in Germany with regard to sociodemographic characteristics. Considering clinical characteristics, the situation seems to be more complex and patterns of similarities and 
differences are heterogenous. The integrative anthroposophic pediatric departments show a broad catchment area all over Germany, with a majority of patients being from former Western Germany. Larger catchment areas for the integrative anthroposophic pediatric hospitals are merely covered by severe and chronic diseases.

\section{Abbreviations}

Destatis: German Federal Statistical Office; IAH: Integrative anthroposophic pediatric hospitals; ICD: International Classification of Diseases; IM: Integrative Medicine; InEK: Institute for the Hospital Reimbursement System; M: Mean; N: Sample size; NCCIH: National Center for Complementary and Integrative Health; SD: Standard deviation; SPSS: Statistical Package for the Social Sciences; STROBE: Strengthening the Reporting of Observational Studies in Epidemiology

\section{Acknowledgements}

We thank the Christophorus and MAHLE foundation for the support of this study. We would like to thank Dr. Katja Boehm for her editorial support. This paper is written in partial fulfilment of the requirements of the University of Witten/Herdecke for the M.D. degree of Katharina Fetz.

\section{Authors' contributions}

KF conceptualized and designed the study, performed data parametrization and all statistical analyses and drafted the initial manuscript. SA made substantial contributions to data parametrization and illustration. MS and TJZ made substantial contributions to concept and design of the study, coordinated and supervised data collection. JV coordinated and supervised data collection. TO and AL conceptualized and designed the study, coordinated and supervised data collection.

All authors were involved in drafting the manuscript and revising it critically for important intellectual content; all authors gave final approval of the final version to be published. Each author takes public responsibility and accepts accountability for those portions of the content with which they were substantially involved as described above. All authors read and approved the final manuscript.

\section{Authors' information}

KF is a Psychologist and Medical Researcher. She is a Consultant for Psychometrics, Statistics and Research Methodology. She specializes in Health Research with a focus on Palliative Care, Integrative Medicine, educational and clinical assessment. She is a Research Fellow, Lecturer and PhD student at the Chair of Research Methodology and Statistics, Department for Psychology and Psychotherapy at Witten/Herdecke University. TO is a Professor for Research Methodology and Statistics in Psychology at the Department of Psychology and Psychotherapy at Witten/ Herdecke University, Germany. MS is a Biologist, PhD and Research Fellow at Gemeinschaftskrankenhaus Herdecke. SA is a Statistician and Research Fellow at the Chair for Research Methodology and Statistics in Psychology at the Department of Psychology and Psychotherapy at Witten/Herdecke University, Germany. JV is head of ARCIM Institute for Academic Research in Integrative Medicine and Senior Physician at the department of Pediatrics at Filderklinik Filderstadt. TJZ Senior Physician at the department of Pediatrics at Gemeinschaftskrankenhaus Herdecke. AL is a Professor for Integrative Pediatrics at Witten/Herdecke University, Germany and head of the department of Pediatrics at Gemeinschaftskrankenhaus Herdecke.

\section{Funding}

The project was financially supported by the MAHLE Stiftung (grant number: 150096) and the Christophorus Stiftung, Germany (Nr. 335). All authors have no financial relationships relevant to this article to disclose. The funding bodies had no influence on the design of the study and collection, analysis, and interpretation of data and in writing the manuscript.

\section{Availability of data and materials}

Raw data are available only for analysis purposes and only to dedicated staff of our research group. As the original data is patient hospital data we have no permission to share it.

\section{Ethics approval and consent to participate}

The present study is a non-invasive, retrospective cohort study and data were collected as part of routine diagnosis and treatment which was not set up as a study or research project. There was no necessity to obtain a vote from a research ethics committee $[57,58]$. This procedure is in accordance with section 15 paragraph 1 of the Model Professional Code for Physicians in Germany [59]. The declaration of Helsinki and the rules for data protection and data security and good epidemiological practice were fully applied [58]. We obtained approval for the scientific use of clinical routine data from the commissary for data privacy protection from the Gemeinschaftskrankenhaus Herdecke and the Filderklinik Filderstadt. Data was anonymized at the point of data acquisition for retrospective analysis.

\section{Consent for publication}

na.

\section{Competing interests}

The authors have no conflicts of interest to disclose.

\section{Author details}

${ }^{1}$ Department of Psychology and Psychotherapy, Chair of Research Methodology and Statistics in Psychology, Witten/Herdecke University, Alfred-Herrhausen-Straße 50, 58448 Witten, Germany. ${ }^{2}$ Department of Pediatrics, Gemeinschaftskrankenhaus Herdecke, Gerhard-Kienle-Weg 4, 58313 Herdecke, Germany. ${ }^{3}$ ARCIM Institute Academic Research in Complementary and Integrative Medicine, Filderstadt, Germany. ${ }^{4}$ Department of Neonatology, University Hospital Tuebingen, Calwerstraße 7, 72076 Tübingen, Germany. ${ }^{5}$ Department of Pediatric Oncology and Hematology, University Hospital Essen, Hufelandstr.55, 45147 Essen, Germany. ${ }^{6}$ Professorship for Integrative Pediatrics, Institute for Integrative Medicine, Witten/Herdecke University, Alfred-Herrhausen-Straße 50, 58448 Witten, Germany.

Received: 4 March 2019 Accepted: 19 November 2019

Published online: 03 December 2019

\section{References}

1. Witt CM, Chiaramonte D, Berman S, Chesney MA, Kaplan GA, Stange KC, et al. Defining health in a comprehensive context: a new definition of integrative health. Am J Prev Med. 2017;53:134-7.

2. Ramesh G, Gerstbacher D, Arruda J, Golianu B, Mark J, Yeh A. Pediatric integrative medicine in academia: Stanford Children's experience. Children. 2018;5:168.

3. Witt CM, Pérard M, Berman B, Berman S, Birdsall TC, Defren H, et al. Using the framework of corporate culture in "mergers" to support the development of a cultural basis for integrative medicine-guidance for building an integrative medicine department or service. Patient Prefer Adherence. 2015:9:113.

4. Anheyer D, Anheyer M, Finetti C, Dobos G, Cramer H. Implementierung von Phytotherapie in eine Akutklinik für Kinder-und Jugendmedizin. Z Für Phytother. 2018;39:251-6.

5. Beer A-M, Uehleke B, Wiebelitz KR. The history of inpatient care in German departments focussing on natural healing. Evid Based Complement Alternat Med. 2013;2013.

6. Eckert M, Amarell C, Anheyer D, Cramer H, Dobos G. Integrative pediatrics: successful implementation of integrative medicine in a German hospital setting —concept and realization. Children. 2018:5:122

7. Huber BM, Schneider R, Bapst V, Wildhaber J. Integrative Pädiatrie am HFR Freiburg - Kantonsspital. Paediatrica. 2018; Vol. 29 Nr. 12018.

8. Längler A, Zuzak TJ. Complementary and alternative medicine in paediatrics in daily practice — a European perspective. Complement Ther Med. 2013;21:S26-33.

9. von Schoen-Angerer T, Vagedes J, Schneider R, Vlach L, Pharisa C, Kleeb S, et al. Acceptance, satisfaction and cost of an integrative anthroposophic program for pediatric respiratory diseases in a Swiss teaching hospital: an implementation report. Complement Ther Med. 2017.

10. Zuzak TJ, Boňková J, Careddu D, Garami M, Hadjipanayis A, Jazbec J, et al. Use of complementary and alternative medicine by children in Europe: published data and expert perspectives. Complement Ther Med. 2013;21:S34-47.

11. Zuzak TJ, Zuzak-Siegrist I, Simões-Wüst AP, Rist L, Staubli G. Use of complementary and alternative medicine by patients presenting to a paediatric emergency department. Eur J Pediatr. 2009;168:431-7. 
12. Jani AA, Trask J, Ali A. Integrative medicine in preventive medicine education: competency and curriculum development for preventive medicine and other specialty residency programs. Am J Prev Med. 2015;49:S222-S229.

13. Armishaw J, Grant CC. Use of complementary treatment by those hospitalised with acute illness. Arch Dis Child. 1999;81:133-7.

14. Chan E, Rappaport LA, Kemper KJ. Complementary and alternative therapies in childhood attention and hyperactivity problems. J Dev Behav Pediatr. 2003;24:4-8.

15. Highfield ES, McLellan MC, Kemper KJ, Risko W, Woolf AD. Integration of complementary and alternative medicine in a major pediatric teaching hospital: an initial overview. J Altern Complement Med. 2005;11:373-80.

16. Kemper KJ, Sarah R, LicAc MPH, Silver-Highfield E, Xiarhos E, Barnes L, et al. On pins and needles? Pediatric pain patients' experience with acupuncture. Pediatrics. 2000;105(Supplement 3):941-7.

17. Kemper KJ, Wornham WL. Consultations for holistic pediatric services for inpatients and outpatient oncology patients at a children's hospital. Arch Pediatr Adolesc Med. 2001;155:449-54.

18. Ottolini MC, Hamburger EK, Loprieato JO, Coleman RH, Sachs HC, Madden $\mathrm{R}$, et al. Complementary and alternative medicine use among children in the Washington. DC area Ambul Pediatr. 2001;1:122-5.

19. Roth I, Highfield L, Cuccaro P, Wells R, Misra S, Engebretson J. Employing evidence in evaluating complementary therapies: findings from an ethnography of integrative pain Management at a Large Urban Pediatric Hospital. J Altern Complement Med. 2019;25:S95-S105.

20. Sanders H, Davis MF, Duncan B, Meaney FJ, Haynes J, Barton LL. Use of complementary and alternative medical therapies among children with special health care needs in southern Arizona. Pediatrics. 2003;111:584-7.

21. Sawni-Sikand A, Schubiner $H$, Thomas RL. Use of complementary/alternative therapies among children in primary care pediatrics. Ambul Pediatr. 2002;2:99-103.

22. Kemper KJ, Gardiner P, Birdee GS. Use of complementary and alternative medical therapies among youth with mental health concerns. Acad Pediatr. 2013;13:540-5

23. Kundu A, Tassone RF, Jimenez N, Seidel K, Valentine JK, Pagel PS. Attitudes, patterns of recommendation, and communication of pediatric providers about complementary and alternative medicine in a large metropolitan children's hospital. Clin Pediatr (Phila). 2011;50:153-8.

24. McClafferty H, Vohra S, Bailey M, Brown M, Esparham A, Gerstbacher D, et al. Pediatric integrative medicine. Pediatrics. 2017;140:e20171961.

25. Stubblefield S. Survey of complementary and alternative medicine in pediatric inpatient settings. Complement Ther Med. 2017;35:20-4.

26. Vohra S, Surette S, Mittra D, Rosen LD, Gardiner P, Kemper KJ. Pediatric integrative medicine: pediatrics' newest subspecialty? BMC Pediatr. 2012;12:123.

27. Bishop FL, Prescott P, Chan YK, Saville J, von Elm E, Lewith GT. Prevalence of complementary medicine use in pediatric cancer: a systematic review. Pediatrics. 2010;125:768-76

28. Shapiro S, Rapaport R. The role of complementary and alternative therapies in pediatric diabetes. Endocrinol Metab Clin N Am. 2009;38:791-810.

29. Gottschling S, Gronwald B, Schmitt S, Schmitt C, Längler A, Leidig E, et al. Use of complementary and alternative medicine in healthy children and children with chronic medical conditions in Germany. Complement Ther Med. 2013;21:S61-9.

30. Şenel HG. Parents' views and experiences about complementary and alternative medicine treatments for their children with autistic spectrum disorder. J Autism Dev Disord. 2010;40:494-503.

31. Vieger AM, Blink M, Tromp E, Benninga MA. Use of complementary and alternative medicine by pediatric patients with functional and organic gastrointestinal diseases: results from a multicenter survey. Pediatrics. 2008;122:e446-51.

32. Barnes PM, Bloom B, Nahin RL, Stussman BJ. Costs of complementary and alternative medicine (CAM) and frequency of visits to CAM practitioners, United States, 2007. 2009.

33. Bethell C, Kemper KJ, Gombojav N, Koch TK. Complementary and conventional medicine use among youth with recurrent headaches. Pediatrics. 2013;:peds-2013.

34. Birdee GS, Phillips RS, Davis RB, Gardiner P. Factors associated with pediatric use of complementary and alternative medicine. Pediatrics. 2010;:peds-2009.

35. Black LI, Clarke TC, Barnes PM, Stussman BJ, Nahin RL. Use of complementary health approaches among children aged 4-17 years in the United States: National Health Interview Survey, 2007-2012. Natl Health Stat Rep. 2015:"1.

36. Clarke TC, Black LI, Stussman BJ, Barnes PM, Nahin RL. Trends in the use of complementary health approaches among adults: United States, 2002-2012. Natl Health Stat Rep. 2015;:1.
37. Simkin DR, Popper CW. Overview of integrative medicine in child and adolescent psychiatry. Child Adolesc Psychiatr Clin. 2013;22:375-80.

38. Hagen LE, Schneider R, Stephens D, Modrusan D, Feldman BM. Use of complementary and alternative medicine by pediatric rheumatology patients. Arthritis Care Res Off J Am Coll Rheumatol. 2003;49:3-6.

39. Ottolini M, Hamburger E, Loprieto J. Alternative medicine use among children in the Washington DC area. San Franc Paediatr Acad Soc. 1999.

40. Kruse S, Schönauer A, Dorcsi-Ulrich M, Rosenecker J. Which role does homeopathy play in the project "integrative pediatrics" at three children's hospitals in Germany? Allg Homöopath Ztg. 2017;262:KF02-1.

41. Kruse S, Dorcsi-Ulrich M, Lucae C. 10 Jahre Homöopathie am Dr. von Haunerschen Kinderspital. Allg Homöopath Ztg. 2006;251:11-20.

42. Kienle GS, Albonico H-U, Baars E, Hamre HJ, Zimmermann P, Kiene H. Anthroposophic medicine: an integrative medical system originating in Europe. Glob Adv Health Med. 2013;2:20-31.

43. Schwermer M, Längler A, Fetz K, Ostermann T, Zuzak TJ. Anthroposophic medicine in the treatment of pediatric pseudocroup: a systematic review. Complement Ther Med. 2017.

44. Schwermer M, Längler A, Fetz K, Ostermann T, Zuzak TJ. Management of Acute Gastroenteritis in children: a systematic review of Anthroposophic therapies. Complement Med Res. 2018.

45. Wopker PM, Schwermer M, Sommer S, Längler A, Fetz K, Ostermann T, et al. Complementary and alternative medicine in the treatment of acute bronchitis in children: A systematic review. Complement Ther Med. 2019;102217.

46. Adams EK, Houchens R, Wright GE, Robbins J. Predicting hospital choice for rural Medicare beneficiaries: the role of severity of illness. Health Serv Res. 1991;26:583.

47. Beer AM, Ostermann T. On the use of classical naturopathy and complementary medicine procedures in hospitals and clinics practicing gynecology and obstetrics in Germany. Gynecol Obstet Investig. 2003;55:73-81.

48. Association GA. Of the WM. World medical association declaration of Helsinki: ethical principles for medical research involving human subjects. J Am Coll Dent. 2014;81:14.

49. Von Elm E, Altman DG, Egger M, Pocock SJ, Gøtzsche PC, Vandenbroucke $J P$, et al. The strengthening the reporting of observational studies in epidemiology (STROBE) statement: guidelines for reporting observational studies. PLOS Med. 2007;4:e296.

50. Ostermann T, Blaser G, Bertram M, Michalsen A, Matthiessen PF, Kraft K. Effects of rhythmic embrocation therapy with solum oil in chronic pain patients: a prospective observational study. Clin J Pain. 2008;24:237-43.

51. Ranger A, Helmert E, Bott TS, Ostermann T, Als H, Bassler D, et al. Physiological and emotional effects of pentatonic live music played for preterm neonates and their mothers in the newborn intensive care unit: a randomized controlled trial. Complement Ther Med. 2018:41:240-6.

52. Edelhäuser F, Hak F, Kleinrath U, Lühr B, Matthiessen PF, Weinzirl J, et al. Impact of colored light on cardiorespiratory coordination. Evid Based Complement Alternat Med. 2013;2013.

53. Ehara A. Children's access to major hospitals estimated to provide pediatric inpatient services 24 ha day in Japan. Eur J Pediatr. 2018;177:559-65.

54. Ruhe A-K, Wager J, Hirschfeld G, Zernikow B. Household income determines access to specialized pediatric chronic pain treatment in Germany. BMC Health Serv Res. 2016;16:140.

55. Judge A, Welton NJ, Sandhu J, Ben-Shlomo Y. Geographical variation in the provision of elective primary hip and knee replacement: the role of sociodemographic, hospital and distance variables. J Public Health. 2009;31:413-22.

56. van den Berg N, Radicke F, Stentzel U, Hoffmann W, Flessa S. Economic efficiency versus accessibility: planning of the hospital landscape in rural regions using a linear model on the example of paediatric and obstetric wards in the northeast of Germany. BMC Health Serv Res. 2019;19:245.

57. Hearnshaw H. Comparison of requirements of research ethics committees in 11 European countries for a non-invasive interventional study. BmJ. 2004:328:140-1.

58. Swart E, Gothe H, Geyer S, Jaunzeme J, Maier B, Grobe TG, et al. Gute Praxis Sekundärdatenanalyse (GPS): Leitlinien und Empfehlungen. Das Gesundheitswesen. 2015;77:120-6.

59. Ratzel R, Lippert H-D, Prütting J. (Muster-) Berufsordnung für die in Deutschland tätigen Ärztinnen und Ärzte-MBO-Ä 1997-. In: Kommentar zur (Muster-) Berufsordnung für die in Deutschland tätigen Ärztinnen und Ärzte-MBO-Ä 1997. Springer; 2018. p. 7-22.

\section{Publisher's Note}

Springer Nature remains neutral with regard to jurisdictional claims in published maps and institutional affiliations. 